\title{
Pure Erythroid Leukaemia- Report of An Extremely Rare Case with Dismal Prognosis
}

\author{
SMKN BEGUM $^{\mathrm{a}}$, MA KHAN ${ }^{\mathrm{b}}$
}

\begin{abstract}
:
Pure erythroid leukaemia (PEL) is a rare and aggressive form of acute leukaemia whose biology remains poorly characterized. The category of acute erythroid leukaemia was signiûcantly revised in the 2016 revision to the World Health Organization (WHO) classiûcation of myeloid neoplasms. In the previous $2008 \mathrm{WHO}$ classiûcation, acute erythroid leukaemia was categorized into two subtypes: erythroleukaemia and pure erythroid leukaemia (PEL), whereas in the 2016 WHO update, erythroleukaemia was merged into myelodysplastic syndrome and PEL becomes the only type of acute erythroid leukaemia. De novo pure erythroid leukaemia is a disease of adults (median age 68
\end{abstract}

\section{Introduction:}

The 2016 revised World Health Organization (WHO) classification of hematological malignancies recognizes pure erythroid leukemia (PEL) as the sole type of acute leukemia with bona fide erythroid differentiation. Under this classification, a diagnosis of PEL requires $>80 \%$ immature erythroid precursors with e" $30 \%$ proerythroblasts and $<20 \%$ myeloblasts. PEL is now the sole type of acute erythroid leukemia and it falls under the category of AML, not otherwise specified according to the 2016 revision of WHO classification. ${ }^{1,2}$ According to the 2008 WHO classiûcation, PEL was included in the broader category of acute erythroid leukemia, which was divided into two subtypes: erythroleukemia (erythroid/myeloid) and PEL. ${ }^{2}$ Both subtypes had been characterized by a predominant erythroid population and they differed in two main aspects: namely, the presence or absence of a signiûcant myeloblast component and whether or not erythroid maturation is arrested. Thus, although both types of

a. Dr. SM Khodeza Nahar Begum, Department of Histopathology, Bangladesh Specialized Hospital

b. Dr. MA Khan, Department of Hematology, Dhaka Medical College \& Hospital

Address for Correspondence: S M khodeza Nahar Begum, Department of Histopathology, Bangladesh specialized hospital, Shyamoli, Dhaka, E mail :khodeza33@hotmail.com

Receive: 01 December, 2020

Accept: 21 August, 2021 years), exhibits a striking male predominance, is universally associated with an abnormal karyotype and has an exceedingly poor overall median survival of 1.4 months. Given the limited number of reports of this rare and diagnostically challenging entity, we report clinicopathologic characteristics of a case of PEL, diagnosis was made by the bone marrow morphology and immunophenotyping.

Key Words: Pure erythroid leukaemia (PEL), Erythroid precursors, WHO classification 2016, Erythroleukemia, Myelodysplastic syndrome

(J Bangladesh Coll Phys Surg 2021; 39: 266-268)

DOI: https://doi.org/10.3329/jbcps.v39i4.55948

acute erythroid leukaemia show a signiûcant erythroid proliferation, erythroid cells in erythroleukemia retain the capacity for sequential maturation, whereas erythroid cells in PEL have maturation arrest and consist of undiferentiated erythroid precursors or proerythroblasts. In latest nomenclature for erythroleukemia (erythroid/myeloid) is considered as myelodysplastic syndrome (MDS) with excess blasts$2 .{ }^{2} \mathrm{PEL}$ is a rare type of acute leukaemia having a clinically aggressive course. The median survival being only 3 months. ${ }^{3}$ Here, we report a case of PEL.

\section{Case Report:}

An 82-year-old male presented with complaints of fatigue, generalized body aches and pain during the previous weeks. He had no fever, chills or weight loss. The patient was hypertensive and on medication. There was no other significant medical history. He had no family history of malignancy. He smoked one pack daily for many years. Physical examination revealed pallor and a localized swelling and tenderness at left lower rib. There were no petechiae, ecchymosis or gum bleeding. There was no palpable lymphadenopathy. Rest of the physical examination was normal except mild splenomegaly.

Complete blood count showed pancytopenia, with a white blood cell count of $3.5 \times 103 / 1 / 4 \mathrm{~L}$, a hemoglobin level of $6.4 \mathrm{~g} / \mathrm{dL}$ and a platelet count of $30.0 \times 103 / 1 / 4 \mathrm{~L}$. 
Bone marrow aspiration revealed blood tap. Bone marrow trephine biopsy was performed. H\&E stained slides revealed a markedly hypercellular marrow essentially replaced by sheets and trabeculae of monomorphic cells having high nuclear cytoplasmic ratio, eccentric nuclei with fine chromatin pattern, occasional prominent nucleoli and amphophilic cytoplasm. Initial suspicion was metastatic poorly differentiated carcinoma.

On immunophenotyping cells were found nonreactive to Pancytokeratin(AE1/AE3), EMA, CD138, MUM1 and CD45 (Figure 1). A second set of immunostains were applied. The cells were found negative to Melan A and HEP per1 but strongly reactive to CD71(85\%) with focal positivity or negative to myeloperoxidase (MPO) (Figure 2). CD71 showed uniform strong membrane positivity in the pronormoblastic cells. Sometime MPO showed minor focal positivity $(<5 \%)$. Flow cytometric analysis of the bone marrow aspirate also revealed numerous immature cells, which were positive for CD 36 and glycophorin-A but lack of myeloid associated markers, consistent with erythroid precursors. The patient died within a month of diagnosis before starting any chemotherapy.

\section{Discussion:}

According to the revised fourth edition WHO classification of acute myeloid leukaemia, pure erythroid leukaemia is now the sole type of acute erythroid leukaemia. The diagnosis of this rare entity is often challenging and the cytologic overlap with nonneoplastic (eg, megaloblastic anaemia) and neoplastic entities (e.g., other types of acute leukaemia and nonhematopoietic malignancies) warrants a significant degree of clinical, laboratory, immunophenotypic and genetic investigation. De novo pure erythroid leukaemia is a disease of adults (median age 68 years), exhibits a striking male predominance. ${ }^{4}$

In PEL there is neoplastic proliferation of immature cells committed solely to an erythroid lineage with no increase in myeloblasts in the bone marrow. 5,6 Patients usually present with profound anaemia, hemorrhages and fever. ${ }^{7}$ In $20-40 \%$ case hepatosplenomegaly can be present. ${ }^{7}$ Our patient had persistent anaemia with mild splenomegaly. Peripheral blood smears of PEL shows nonspecific changes in the majority of cases, circulating erythroblasts may be seen in about a quarter of patients. ${ }^{5}$ Anaemia and thrombocytopenia are commonly observed. ${ }^{3}$ Our patient had sustained pancytopenia and no circulating erythroblasts are seen.

Bone marrow aspirate and biopsy are critical in making the diagnosis of PEL. The bone marrow trephine biopsy specimen of PEL is typically hypercellular and composed of sheets of leukaemic cells that diffusely replace the medullary space. Predominant cells ( $>80 \%)$ are erythroid precursors with left shift and increased proerythroblasts which are the most immature recognizable erythroid precursor. They are medium to large blasts with round nuclei, fine nuclear chromatin, occasional prominent nucleoli, cytoplasm is deep blue and is agranular with variable cytoplasmic vacuolization. An intrasinusoidal or intravascular inûltrate pattern is seen in some cases. Maturing nucleated erythroid cells are signiûcantly decreased and often show dyspoietic features. ${ }^{8}$

The earliest hematopoietic progenitor committed to erythroid differentiation is burst-forming unit erythroid (BFU-E), which comes from megakaryocyte-erythroid progenitor (MEP). BFU-E differentiates into colonyforming unit erythroid (CFU-E), then proerythroblasts, which are the earliest erythroid cells that can be morphologically recognized as erythroid lineage. In PEL, leukaemic cells lose its ability to differentiate and show increased cell survival and proliferation. ${ }^{8}$

Morphologically, the diagnosis of PEL may be difficult in the setting of a suboptimal or inadequate bone marrow aspirate specimen. In our patient repeated marrow aspirate revealed a blood tap and the extent of leukaemic infiltration was evident on the bone marrow core biopsy. The marrow was uniformly hypercellular for age. There was predominance of poorly differentiated cells hardly recognizable as of erythroid type. A wide range of immunostains were applied for cellular characterization. Hematopoietic cell marker CD71 detected erythroid component constituting 85\% with left shifted maturation. On H\&E, recognizable proerythroblast component constituted only about $30 \%$ of the total immature cells. Dysplastic changes were also recognizedwhich revealed a plasmacytoid appearance. Immunostains CD138 and MUM 1 were applied in our case to exclude possibility of plasmablastoma. HEPper1 and Melan A were applied to exclude metastatic hepatocellular carcinoma and melanoma respectively.

Two iron-related proteins, CD71 and ferritin, have recently emerged as sensitive and speciûc markers for erythroid lineage cells. CD71 is a membranous protein involved in iron uptake, and ferritin is a cytoplasmic 
protein that functions as a repository for iron storage. Most body iron is used by erythroid cells for hemoglobin synthesis and is delivered into cells by CD71 at a very early stage of differentiation (BFU-E).${ }^{9}$ Glycophorin A positivity and partial CD36 positivity have also been reported to be consistent with erythroid precursors. ${ }^{10}$ As erythroid progeny arise from bipotent megakaryocyte-erythrocyte progenitors, occasional cases of PEL may show partial expression of antigens associated with megakaryocytic differentiation (e.g., CD41 and CD61). In our case, however we did not detect megakaryocytic antigen expression on the proerythroblasts. Immature erythroid precursors comprise the predominant component in PEL and may morphologically be very primitive to resemble metastatic malignancies or other hematopoietic neoplasms, therefore use of appropriate markers to determine erythroid lineage is crucial.

It is evident from the literature that no speciûc genetic mutations have been described in PEL. It appears that mutations commonly found in other types of AML, such as FLT3, NPM1, and CEBPA, are very rare in PEL. Next generation sequencing were performed on PEL cases for targeted mutation analysis and Interestingly, most of the cases showed TP53 mutations and a Complex Karyotype with Chromosome 17 Abnormalities. ${ }^{8}$ Interestingly, in some cases, there were co-occurrence of both, or double TP53 mutations were also observed. ${ }^{10,11}$

PEL is a very aggressive and rare disease. The approach of treatment of PEL is similar to the approach used for other subtypes of acute myelogenous leukaemia. The standard induction produces complete remission in only $10-40 \%$ cases, which is usually very brief. PEL is a rare disease typically associated with poor prognosis with median survival of 3 months from initial diagnosis. An extensive workup, including clinical history, laboratory studies, morphology, complete immunophenotyping, and cytogenetics is typically required to establish the diagnosis with confidence. As our patient died within a few weeks, cytogenetic study was not done for further establishment of diagnosis. The molecular mechanisms of PEL is highly complex and therefore no appropriate targeted therapy is yet applicable to combat its worse prognosis. Future collaborative studies to identify the molecular defects will contribute to the development of targeted therapies to significantly improve patient outcome.

\section{Acknowledgment:}

The author is grateful to laboratory staff in the Department of Histopathology, Bangladesh specialized hospital for technical assistance for the study.

Conflict of interest:

The authors have no conflict of interest.

\section{References:}

1. Daniel A A, Attilio O, Robert H, Jurgen T, Michael JB, Beau MML et al. The 2016 revision to the World health organization classification of myeloid neoplasms and acute Leukaemia. Blood. 2016; 127 (20): 2391-2405. https:// doi.org/10.1182/blood-2016-03-643544 PMid:27069254

2. Cameron Y, Jeffrey ML, Carlos EBR. Recent Advances in the Diagnosis and Classification of Myeloid Neoplasms Comments on the 2008 WHO Classification. Int J Lab Hematol. 2010 Oct; 32(5): 461-476. https://doi.org/ 10.1111/j.1751-553X.2010.01246.x PMid:20626469 PMCid:PMC4452117

3. Liu W, Hasserjian RP, Hu Y, Zhang L, Miranda RN, Medeiros $\mathrm{LJ}$, et al. Pure erythroid leukaemia: a reassessment of the entity using the 2008 World Health Organization classiûcation. Mod Pathol. 2011; 24: 375-383. https:// doi.org/10.1038/modpathol.2010.194 PMid:21102413

4. Erica F R, Patricia T G, April C, Matthew T H, Kaaren K R. De novo pure erythroid leukaemia: refining the clinicopathologic and cytogenetic characteristics of a rare entity. Mod Pathol. 2018; 31: 705-717 https://doi.org/ 10.1038/modpathol.2017.175 PMid:29327715

5. Wang SA, Hasserjian RP. Erythroid proliferations in myeloid neoplasms. Hum Pathol. 2012; 43: 153-164. https://doi.org/ 10.1016/j.humpath.2011.08.008 PMid:22154053

6. Liu CJ, Hong YC, Yang CF, Liu SH, Gau JP. Clinicopathologic features and outcome of acute erythroid leukaemia based on 2008 revised World Health Organization classiûcation. Leuk Lymphoma. 2012; 53: 289-294. https:/ /doi.org/10.3109/10428194.2011.607526 PMid:21780998

7. Olopade OI, Thangavelu M, Larson RA, Mick R, KowalVern A, Shumacher HR, et al. Clinical, morphologic, and cytogenetic characteristics of 26 patients with acute erythroblastic leukaemia. Blood. 1992; 80: 2873-2882. https://doi.org/10.1182/blood.V80.11.2873.2873 https:// doi.org/10.1182/blood.V80.11.2873. bloodjournal 80112873 PMid: 1450412

8. Wang W, Wang S A, Medeiros L J, Khoury J D. Pure erythroid leukaemia. Am J Hematol. 2017; 92(3):292-296. https:// doi.org/10.1002/ajh.24626 PMid:28006859

9. Mori Y, Chen JY, Pluvinage JV,Seita J, Weissman IL. Prospective isolation of human erythroid lineage-committed progenitors. Proc Natl Acad Sci U S A. 2015;112:96389643. https://doi.org/10.1073/pnas.1512076112 PMid:26195758 PMCid:PMC4534255

10. Aljabry M. Complex Karyotype with Novel Translocation in Pure Erythroid Leukaemia Patient. Hematol Rep. 2015; 7: 56-74. https://doi.org/10.4081/hr.2015.5674 PMid:25852849 PMCid:PMC4378206

11. Bravo G M, Benton C B, Wang S A, Ravandi F, Kadia T M, Cortes J, et al. More than 1 TP53 abnormality is a dominant characteristic of pure erythroid leukaemia. Blood. 2017; 129(18): 2584-2587. https://doi.org/10.1182/blood-201611-749903 PMid:28246192 PMCid:PMC5418636 